\title{
Review of Urban Flood Impact Reduction due to Climate Change Adaption Driven by Urban Planning Management in Pathumthani Province, Thailand
}

\author{
Yaowalak Chanthamas $^{1 *}$, Sutee Anantasuksomsri ${ }^{2}$ and Nij Tontisirin ${ }^{3}$
}

\author{
1 Department of Urban and Regional Planning, Faculty of Architecture, Chulalongkorn \\ University. \\ 2 Faculty of Architecture, Department of Urban and Regional Planning, Chulalongkorn \\ Universit. \\ 3 Faculty of Architecture and Planning, Thammasat University: Rangsit Campus. \\ * Corresponding Author, Email: : koh26.chan@gmail.com
}

Received: Dec 15, 2016; Accepted: Jan 15, 2017

Keywords: Climate change adaptation, urban flood, hazard map, Pathumthani province.

\begin{abstract}
The Province of Pathumthani has played an important role in the Bangkok Metropolitan Region (BMR) in terms of its economics, industry, education, society, and culture in driving the urbanization process. However, the urban areas have been sprawling without control. Some urban areas have expanded to areas with risk of flooding. Especially, in the past 10 years, Pathumthani has suffered from more frequent and more severe floods, which might be affected by climate change. Together with inefficient climate change adaptation plans, the areas with risk of high impacts of flooding have expanded, making the urban settlements in Pathumthani face even higher impacts. The objectives of this research are to examine land use changes in order to understand the direction of urban expansion, to analyze the level of flood impact risk under climate change in Pathumthani by using Sieve Analysis and Geographic Information Systems, and to examine flood adaptation plans and the projections of urban development by using Scenario Analysis. The results show that the flood impact risk of Pathumthani has been higher under climate change, and the areas with flood impact risk have expanded, especially in the western side of Chao Phraya River which covers the majority of the areas in (1) Sam Khok District, (2) Mueang Pathum Thani District, and (3) Lat Lum Kaeo District. Moreover, the results suggest that the direction of urbanization is toward these three districts with high flood impact risk. Thus, climate change adaptation plans are essential for Pathumthani.
\end{abstract}

\section{$1 \quad$ INTRODUCTION}

Located in the north of Bangkok, the province of Pathumthani is one of the provinces in the Bangkok Metropolitan Region (BMR). The province consists of seven districts (Amphoe) (see Figure 1), which can be divided into 60 subdistricts (Tambon) with 529 villages (Mooban) (Department of Provincial Administration, 2016). In the past, agriculture was the main activity of the 
province. Since the 1960's, Pathumthani has transformed from agricultural lands to residential real estate projects, factories, and industrial estates. It has played an important role in the nation's industrial and education development as well as in Bangkok's economic development. The province has been a commuter town of the BMR since past decades. Currently, approximately $25 \%$ of the population in the BMR resides in Pathumthani. Located on lowlying land in the Chaophraya River basin with the river passing through the city, the province has faced challenges with severe flooding in the past decade. Due to a 2011 flood, Pathumthani is one of the provinces with the highest loss and damage because there are many settlements in flood-prone areas. Under the context of climate change, the expansion of this unplanned urbanization and urban sprawl has created more risk-of-flood situations in Pathumthani.

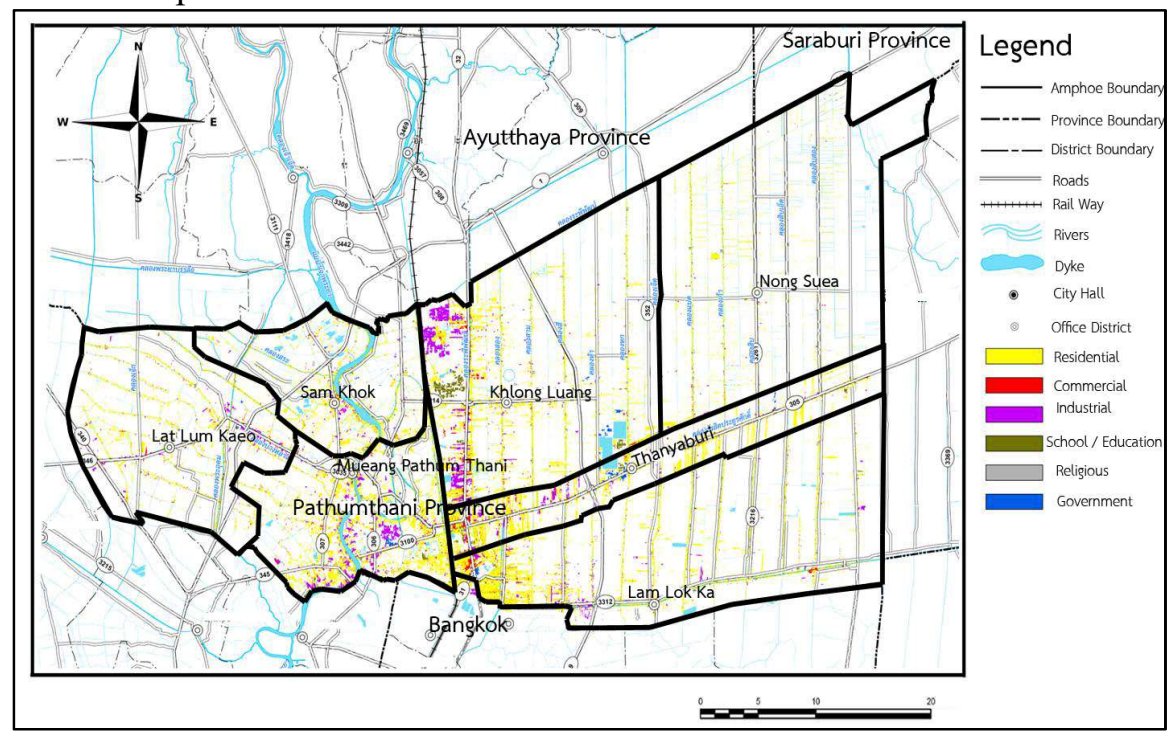

Figure 1. Districts in Pathumthani province (Source: Department of Provincial Administration, 2016)

This study analyzes the relationship of factors affecting the risk of flood impacts and related land use changes of urban areas in the province of Pathumthani, using Geographic Information Systems (GIS). It also studies the adaptation to urban flooding under climate change of communities living in the province. In addition, Scenario Analysis is used to analyze alternative futures of urban flood events in seeking appropriate responding policies. Prospective guidelines and policies on urban planning and flood management are discussed in this paper.

This research aims (1) to examine urban floods, land use changes, urbanization processes and adaptation plans in the province of Pathumthani, (2) to analyze the relationship of urbanization and urban flood impact risk under different flooding levels, (3) to provide scenarios of urban floods in response to land use changes and suggest community adaptation plans.

The main hypotheses are that urban expansion and land use changes increase the flood impact risk, and the role of urban planning can help reduce the risk of flood impacts in Pathumthani. This study has two main research questions: (1) what the impacts of urban expansion and land use change on the risk of flood impactsin Pathumthani are, and (2) what the roles of urban planning on reducing the risk of flood impacts in Pathumthani are. 


\section{LITERATURE REVIEW}

Adaptation has become one of the important issues in current literature on climate change. Adaptation to climate change usually refers to disaster response or coping capacity to natural disaster risks. Risks from natural disasters may stem from both natural and socio-economic factors (Sustainable Development Foundation, 2014). Socio-economic factors encompass a wide range of socio-economic characteristics such as income level, social vulnerability, and coping capacity (APFM, 2008). In the case of flooding in Thailand, man-made causes, in particular unsuitable land uses, and inappropriate land management, such as urban expansion onto flood-prone areas or the development of infrastructure that obstructs floodways, are found to amplify the impacts from natural disasters (Watcharapasakorn, 2013). Understanding these risk factors is an important first step to finding appropriate responses to a natural disaster. Scenario Analysis is also widely used to illustrate alternative futures and assess impacts and appropriate responses to such scenarios.

Many works on climate change adaptation in Thailand focus on land use and land management strategies (Thailand Action Aid International, 2006). For example, Kornissaranukul (2013) found that land use changes in Punpin County in Suratthani could lead to higher risk of flood impacts and proposed a method to determine spatial risk factors using Potential Surface Analysis (PSA). The analysis led to the creation of guidelines that support the community to manage future flood-associated risks.

The research herein is different from other studies on flood impacts regarding land use change in the context of climate change as it conducts a Scenario Analysis to provide input into the study areas' plans and policies for flood management. A map is developed to illustrate the extent of flood impacts and provides a tool for reducing vulnerabilities. The result contributes to capacity building for communities within the study area under development, based on a variety of different parameters.

\section{METHODOLOGY}

This research is part of a larger research project partially funded by the Thailand Development Research Institute (TDRI). Overall, the research project consists of four main components:

\section{Part 1: Examining urbanization process of Pathumthani province}

- Physical data and time line of land use changes to compare two period times, Year 2001 and Year 2011, using Geographic information systems (GIS) with a Spatial Analysis tool.

- Analysis on trends of land use changes and urbanization comparing two time periods, Year 2001 and Year 2011, using GIS with a Spatial Analysis tool.

\section{Part 2: Identifying flood risk areas}

- Collect and analyze data to find flood risk areas using three factors: built up areas, urban communities and land use activities; with two co-factors: Flood Boundary and Flood Depth; and overlay mapping of all data with a Sieve Analysis.

\section{Part 3: Proposing a design by Scenario Analysis}

- Set recommendation guidelines with flood adaptation options, under the conditions of the worst case of flooding in 2011. 
- Set Scenario Analysis using urban planning guidelines under the following three scenarios:

The first scenario: develop Zoning and Building code in risk area zones.

The second scenario: defined catchment area and drainage.

The third scenario: develop structural (hard structure) measures.

- Bring risk map from Part 2 and combine with Flood Boundary and Flood Depth using overlay analysis to classify and specify risk area zones.

Part 4: Reviewing plans, policies and urban management with infrastructure and non-infrastructure measures:

- Collect land use and building use data, including plan, policy and ordinance regulations for analyzing and estimating.

- Collect water management data and guidelines, including plan, policy and ordinance regulations for analyzing and estimating.

- Analysis of potential and limitations of each plan and/or policy, including experts' interviews to summarize the guidelines for most efficient urban planning guidelines and coping situations for flooding in the study area.

For the purpose of completing this research, Part 2 will be the focus of this paper. The analysis utilizes Potential Surface Analysis or Sieve Analysis to identify areas with a high level of flood impact risk in Pathumthani province. It incorporates both physical and socio-economic factors, taking into consideration urban growth and flood prone areas. There are six factors including (1) slope, (2) soil type, (3) land use, (4) access to communities, (5) elevation, and (6) population density. These factors are illustrated in Figure 2 - Figure 7.

Weighting and scoring of these factors are derived from interviews with experts. They can be described as follows:

\section{(1) Slope}

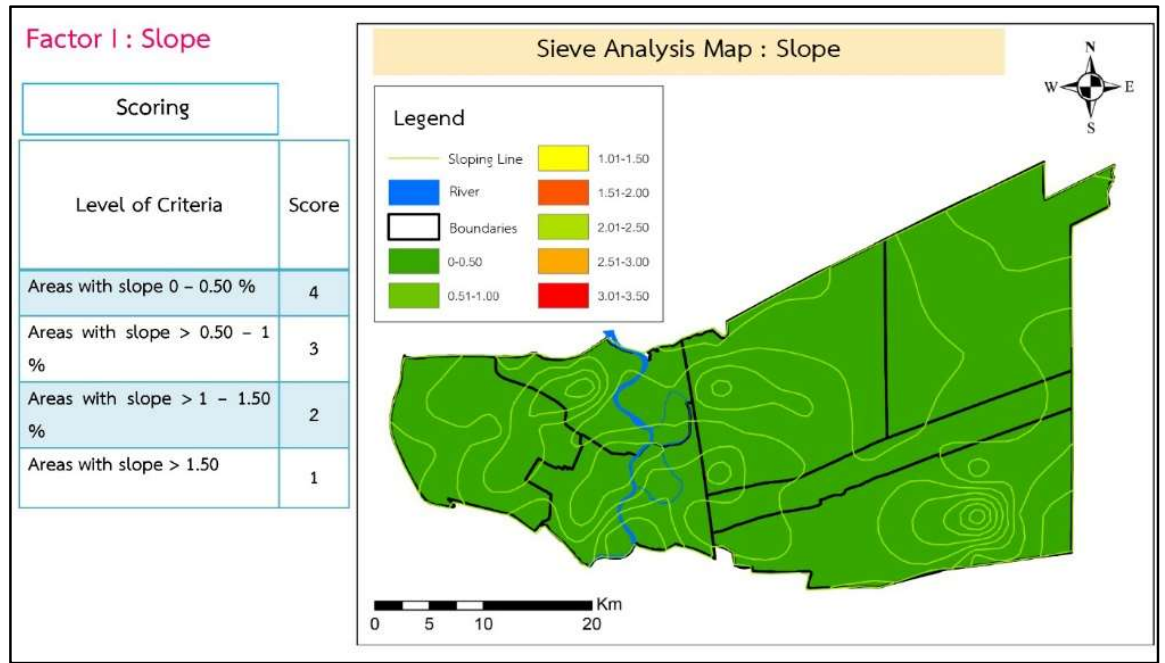

Figure 2. Methodology: Factor for Sieve Analysis (Slope) 
Slope is an important factor for identifying flood risk areas as slope can affect how fast the flood waters can be drained. Areas with a small incline (0$0.5 \%$ ) are considered as high flood risk and scored 4 , while areas with an incline greater than $1.5 \%$ are categorized as low flood risk and scored 1. Areas with an incline of $0.5-1 \%$ and $1-1.5 \%$ are scored 3 and 2 , respectively.

\section{(2) Soil Type}

The type of soil can affect the rate of infiltration. In Pathumthani province, there are two major types of soil: type 8 and 11. Areas with soil that has a lower infiltration rate are categorized as high risk. Soil type 11 has a lower infiltration rate, so it is scored 4 , while soil type 8 is scored 1 .

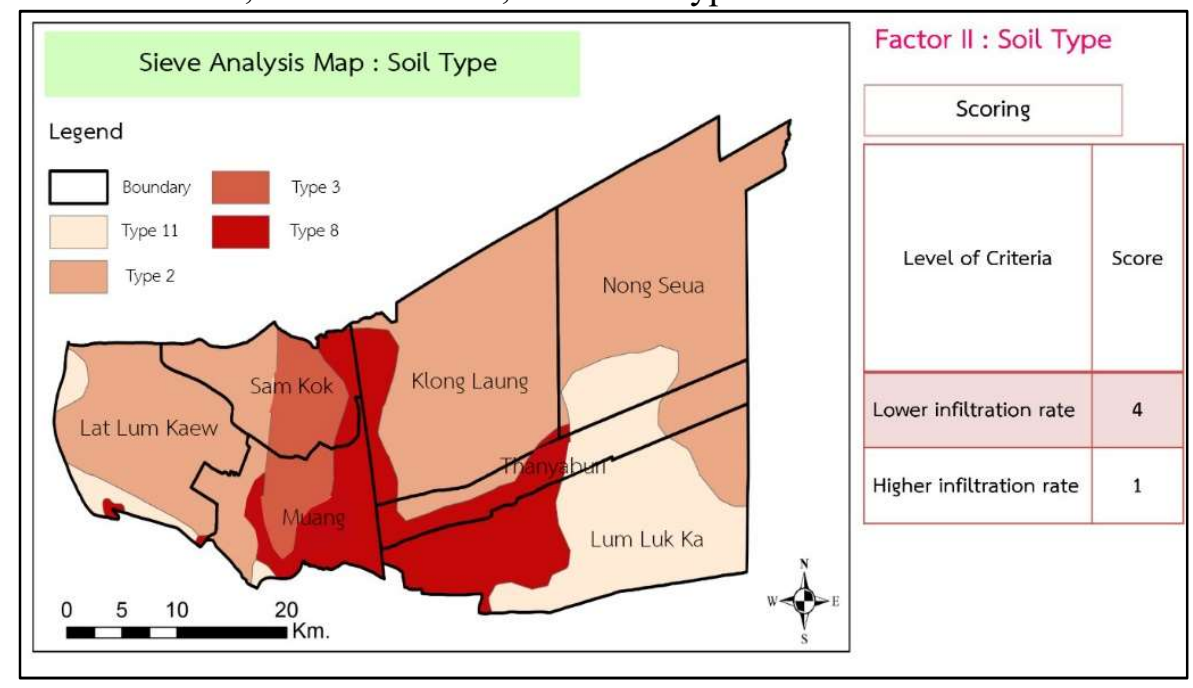

Figure 3. Methodology: Factor for Sieve Analysis (Soil Type)

\section{(3) Land Use}

Different land use types can impose different levels of water usage and drainage. Residential areas are considered to have the highest flood risk (and are scored 4), followed by commercial (scored 3), manufacturing (scored 2), and agricultural (scored 1) land uses consecutively.

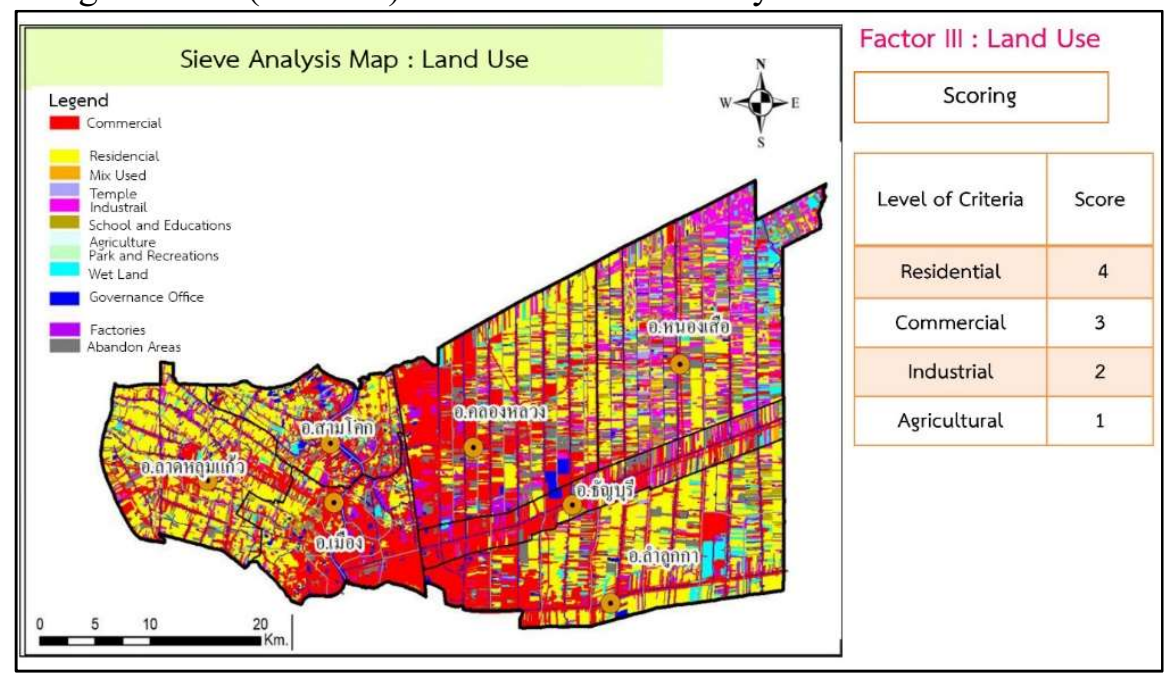

Figure 4. Methodology: Factor for Sieve Analysis (Land Use) 


\section{(4) Access to Communities}

This factor classifies distances from main roads to assess community accessibility. Communities that are located near the main roads have lower risk than communities that are farther away. Communities located farther than 3 kilometers from main roads are scored 4 . Communities near main roads (distance between 0-20 meters) are scored 1 .

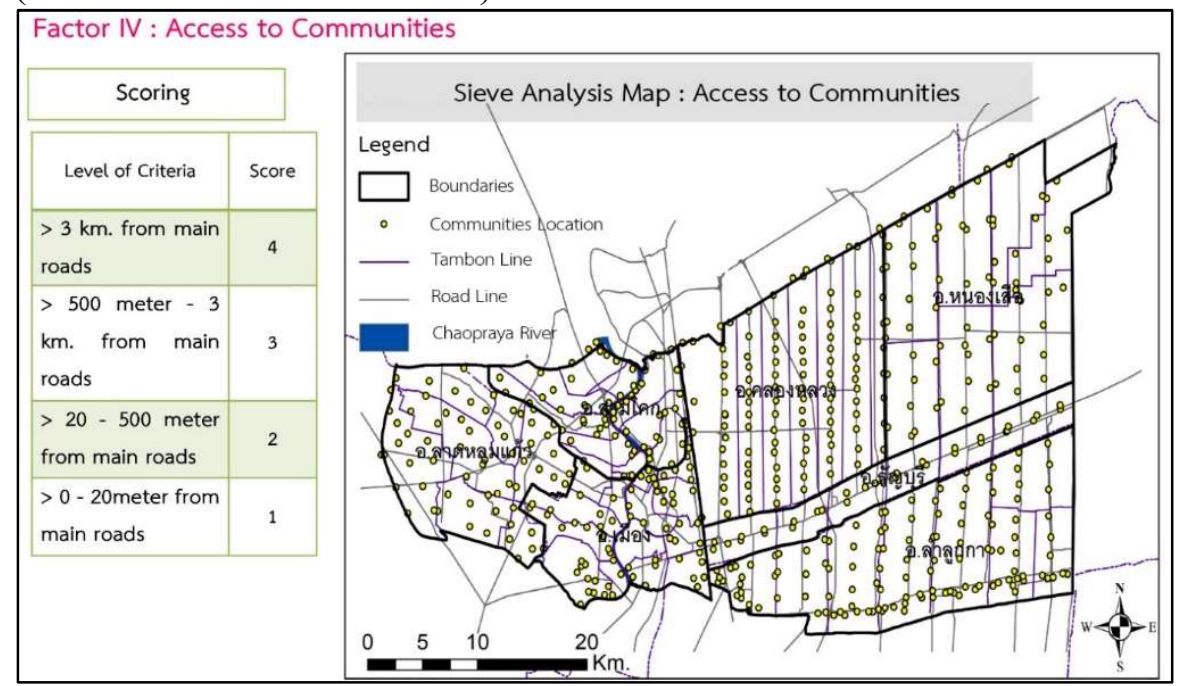

Figure 5. Methodology: Factor for Sieve Analysis (Access to Communities)

\section{(5) Elevation}

Elevation plays an important role in the flood risk of an area. Areas with higher elevation have a lower level of flooding. High elevation (150 meters above sea level) is scored 1 , while the lowest elevation is scored 4 .

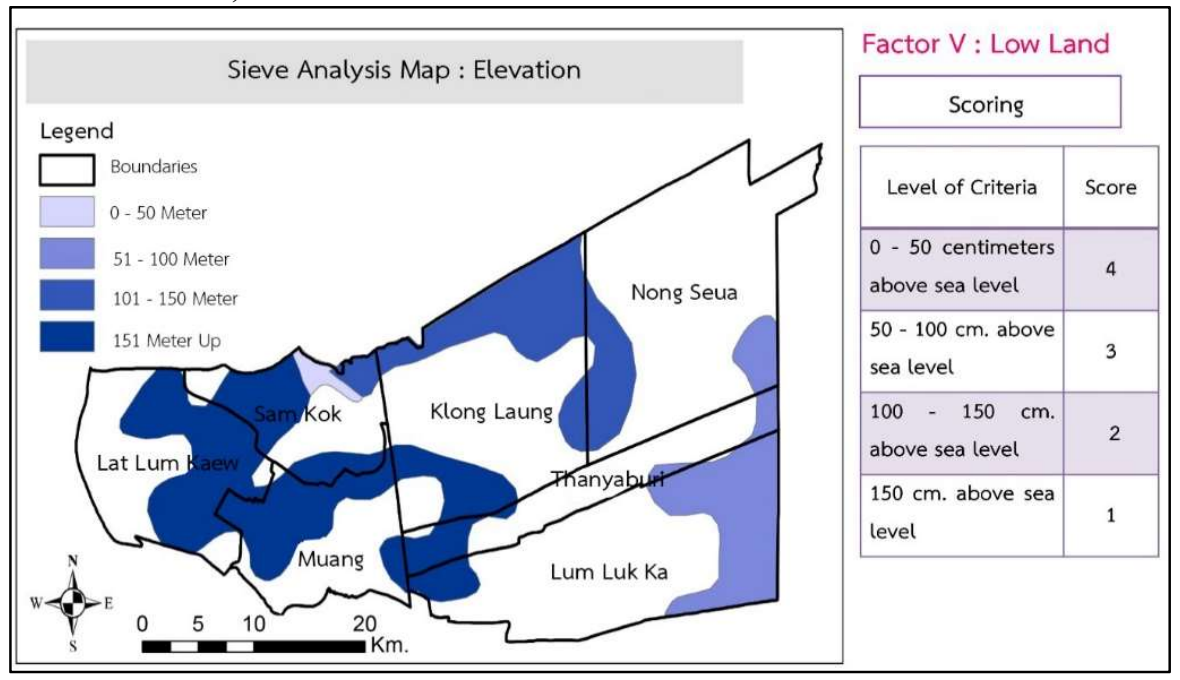

Figure 6. Methodology: Factor for Sieve Analysis (Elevation)

\section{(6) Population Density}

Areas are ranked and scored based on population density. Areas with high population density are considered at high risk of flood impact. High density 
areas are scored 4, followed by large (scored 3), medium (scored 2), and small settlements (scored 1).

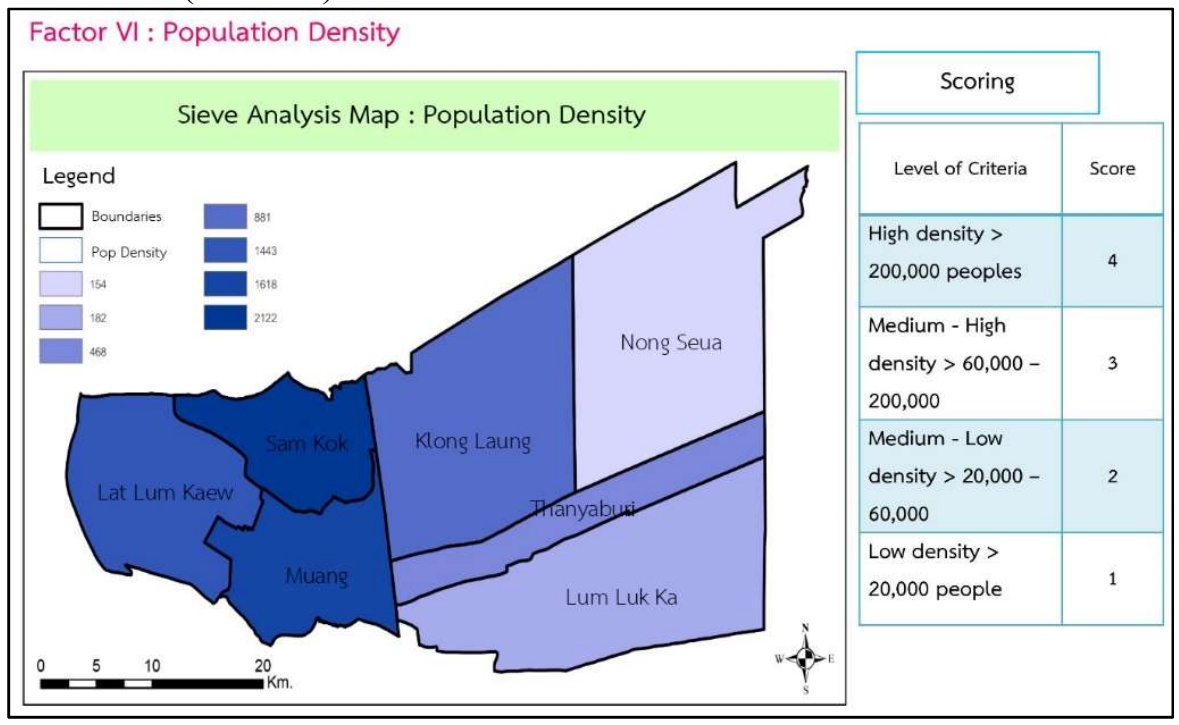

Figure 7. Methodology: Factor for Sieve Analysis (Population Density)

The Sieve Analysis method to analyze flood risk areas using an overlay analysis can be described as follows:

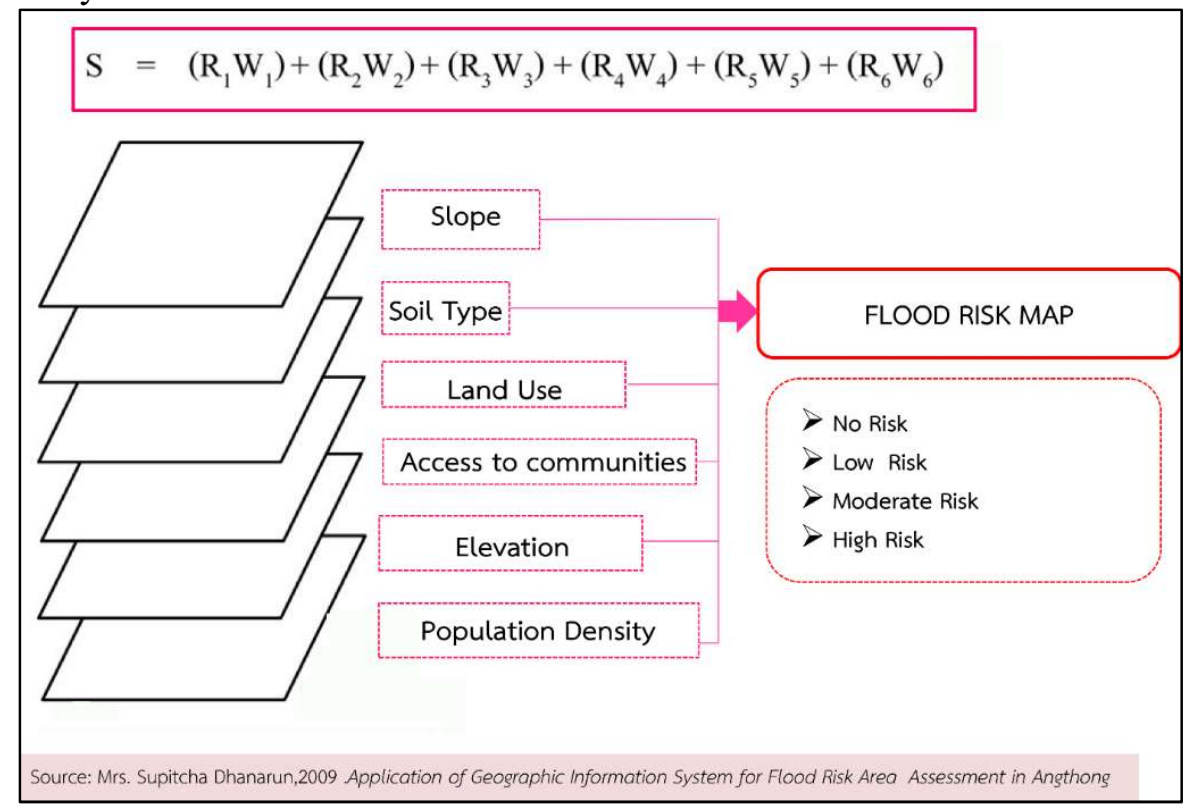




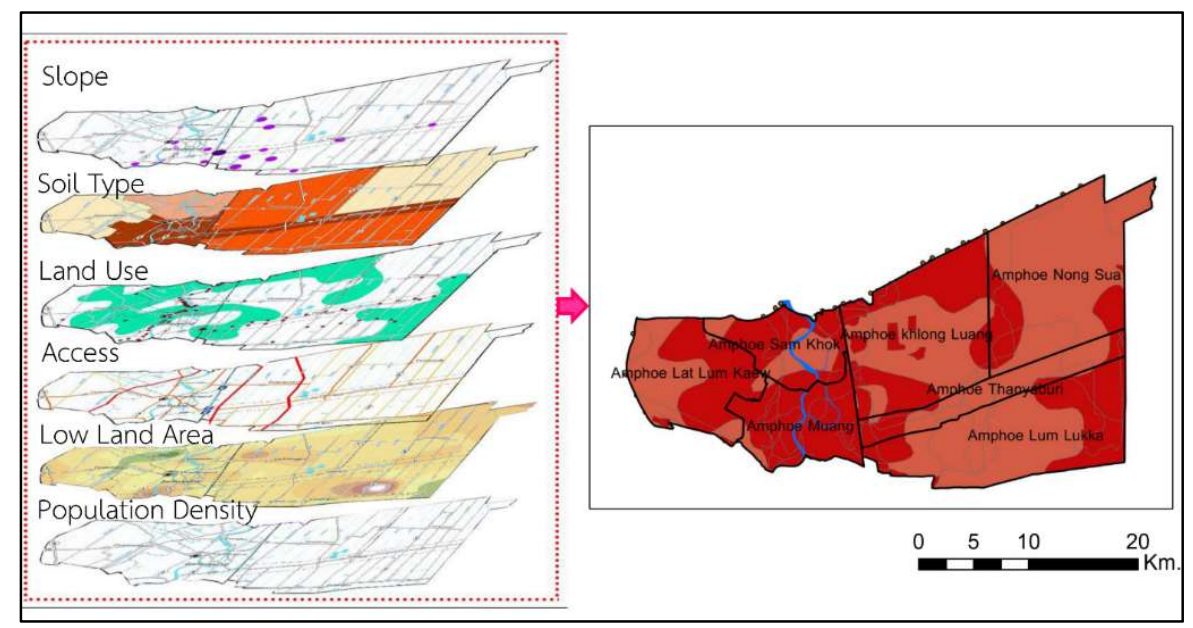

Figure 8. Methodology: Sieve Analysis

The research framework in Figure 9 below describes the analysis process used to develop urban and regional planning measures in Pathumthani province.

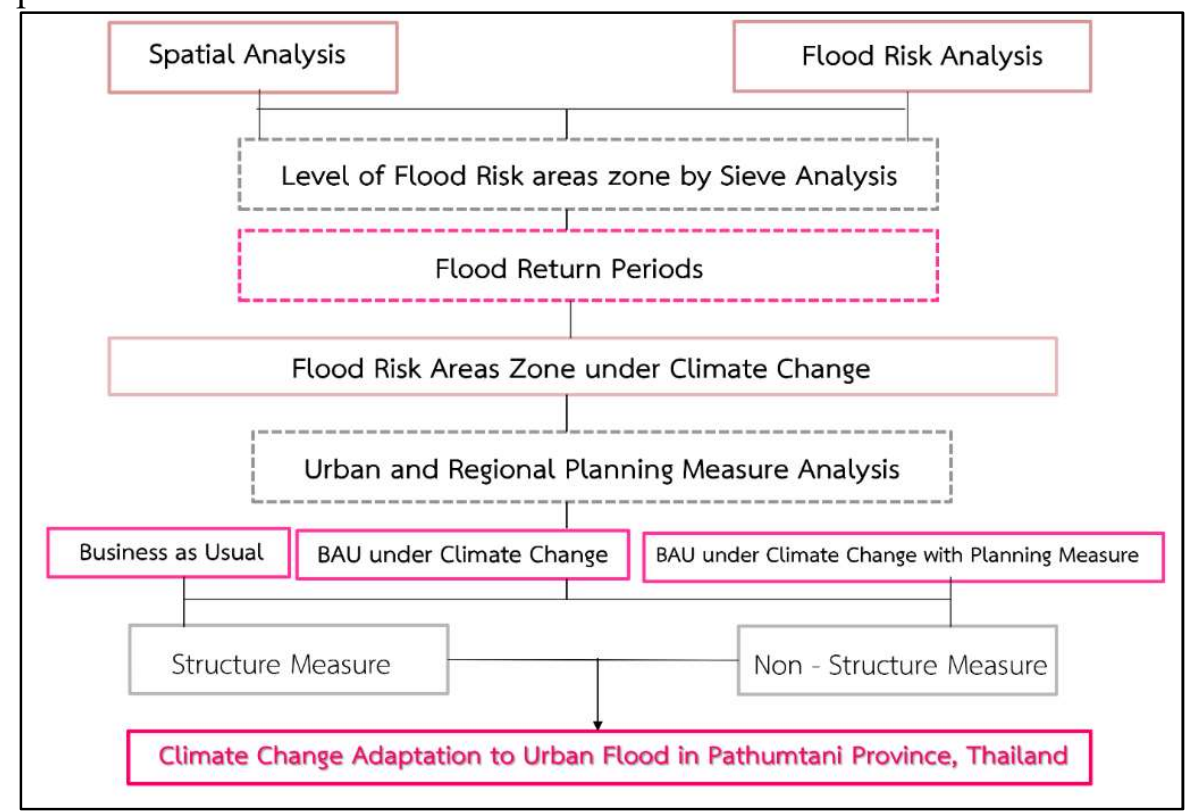

Figure 9. Research Framework

(1) Analytic Hierarchy Process (AHP): Pair-wise comparison by two experts, an Urban Planning Expert and Geo Information Systems Expert (2) Pair-wise comparison matrix 
Table 1. Structure of pairwise comparison matrix.

\begin{tabular}{|c|c|c|c|c|c|c|c|}
\hline \multicolumn{8}{|c|}{ Pair - Wise Comparison Analysis } \\
\hline \multicolumn{8}{|l|}{ Flood Areas Zone } \\
\hline Score & Elevation & Soil Type & Land Use & Access & Flood Return & Population Density & \\
\hline Expert Interview I & 0.207 & 0.095 & 0.282 & 0.235 & 0.112 & 0.069 & \\
\hline Expert Interview II & 0.129 & 0.182 & 0.372 & 0.186 & 0.077 & 0.054 & \\
\hline Total & 0.336 & 0.277 & 0.654 & 0.421 & 0.189 & 0.123 & \\
\hline Conclusion & 0.168 & 0.139 & 0.327 & 0.211 & 0.095 & 0.062 & 1.000 \\
\hline
\end{tabular}

Source: Weighting and scoring by experts.

Table 2. Results of Weighting and Scoring

\begin{tabular}{|c|c|c|c|c|}
\hline \multirow{2}{*}{ Factors } & \multirow{2}{*}{ Index } & \multicolumn{2}{|c|}{ Weighting } & \multirow{2}{*}{ Scoring } \\
\hline & & $(W)$ & (R) & \\
\hline \multirow{4}{*}{ Land Use } & Built - up areas & \multirow{4}{*}{32.7} & 4 & 130.8 \\
\hline & Commercial areas & & 3 & 98.1 \\
\hline & Industrial areas & & 2 & 65.4 \\
\hline & Agriculture areas & & 1 & 32.7 \\
\hline \multirow{4}{*}{ Access } & $>3,000$ meter from road line & \multirow{4}{*}{20.5} & 4 & 82 \\
\hline & $>1,000$ meter from road line & & 3 & 61.5 \\
\hline & $>500$ meter from road line & & 2 & 41 \\
\hline & $<500$ meter from road line & & 1 & 20.5 \\
\hline \multirow{4}{*}{ Slope } & $<0-0.5$ & \multirow{4}{*}{19.9} & 4 & 79.6 \\
\hline & $>0.5-1.0$ & & 3 & 59.7 \\
\hline & $>1.0-1.5$ & & 2 & 39.8 \\
\hline & $>1.5 \mathrm{UP}$ & & 1 & 19.9 \\
\hline \multirow{4}{*}{ Elevations } & Higher $0-50$ meter & \multirow{4}{*}{10.1} & 4 & 40.4 \\
\hline & Higher 50 - 100 meter & & 3 & 30.3 \\
\hline & Higher $100-150$ meter & & 2 & 20.2 \\
\hline & Higher 150 meter Up & & 1 & 10.1 \\
\hline \multirow{2}{*}{ Soil Type } & Rangsit soil type & \multirow{2}{*}{9.5} & 4 & 38 \\
\hline & Thonburi soil type & & 1 & 9.5 \\
\hline \multirow{3}{*}{ Population Density } & $>$ more than 150,000 & \multirow{3}{*}{7.3} & 4 & 29.2 \\
\hline & $>100,000-150,000$ & & 3 & 21.9 \\
\hline & $>50,000-100.000$ & & 2 & 14.6 \\
\hline
\end{tabular}




\begin{tabular}{|l|c|c|c|c|} 
& \multicolumn{2}{|c|}{$<50,000$ Down } & 1 & 7.3 \\
\hline \multicolumn{2}{|c|}{ The level of flood impact risk } & \multirow{2}{*}{ point } \\
\cline { 1 - 3 } Non Risk & represent & $\mathbf{1}$ & point \\
\hline Minor Risk & represent & $\mathbf{2}$ & point \\
\hline Moderate Risk & represent & 3 & point \\
\hline Major Risk & represent & 4 &
\end{tabular}

Built up areas are effected by floods categorized into four flood return periods:

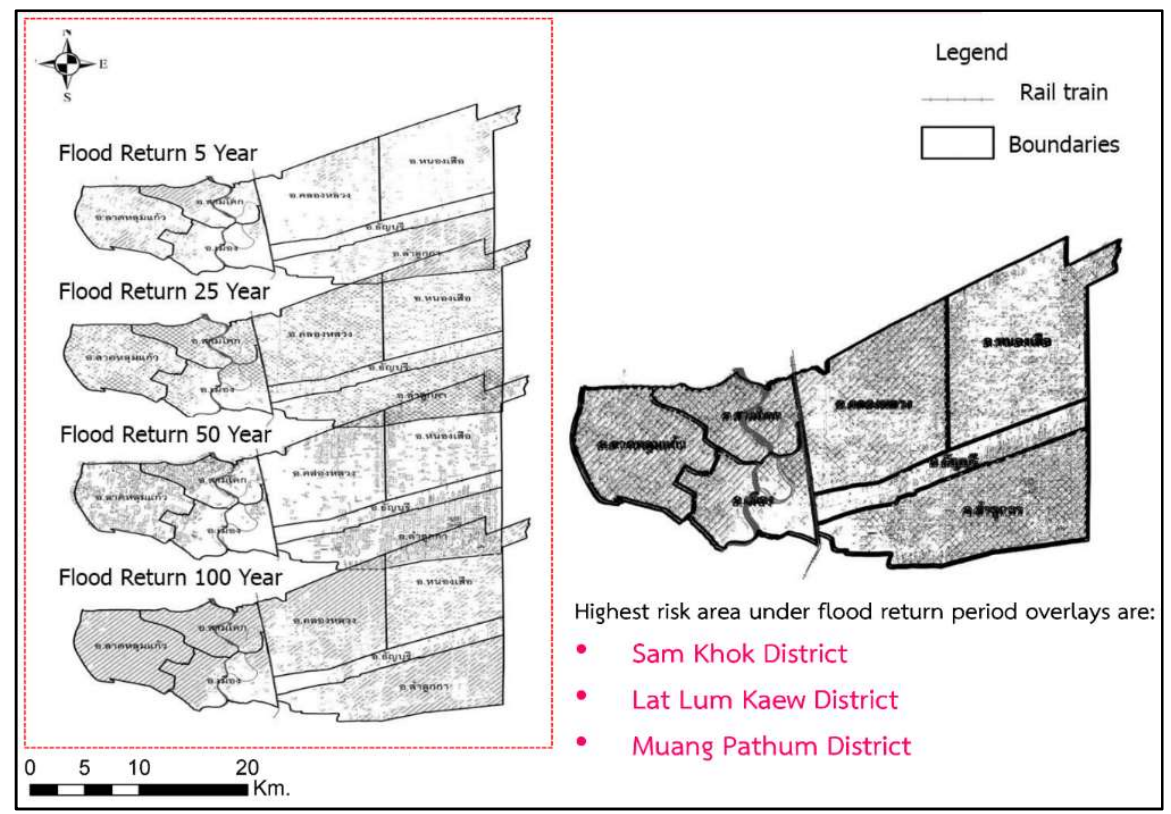

Figure 10. Flood return period in Pathumthani province.

The Sieve Analysis, done using the reclassify tools of ArcGIS, shows the risk of an area being exposed to a flood situation. From the result in Table 1, the main risk factors are land use activities, access and slope. The results in Table 2 also support this finding, with the less influential factors being elevation, soil type and population density.

The results map, see Figure 11, shows the risk classification for areas in Pathumthani, obtained through the Sieve Analysis completed using Spatial Analysis Tools. This research found the spread of flood impact risk to be mostly moderate or high risk areas. It is likely that under climate change conditions risk will only increase, in particular, the frequency of typically low frequency events will increase. Further research will use the results map to identify planning measures that can reduce flood impact risk and be used as a basis for adaptation planning for communities in Pathumthani. 


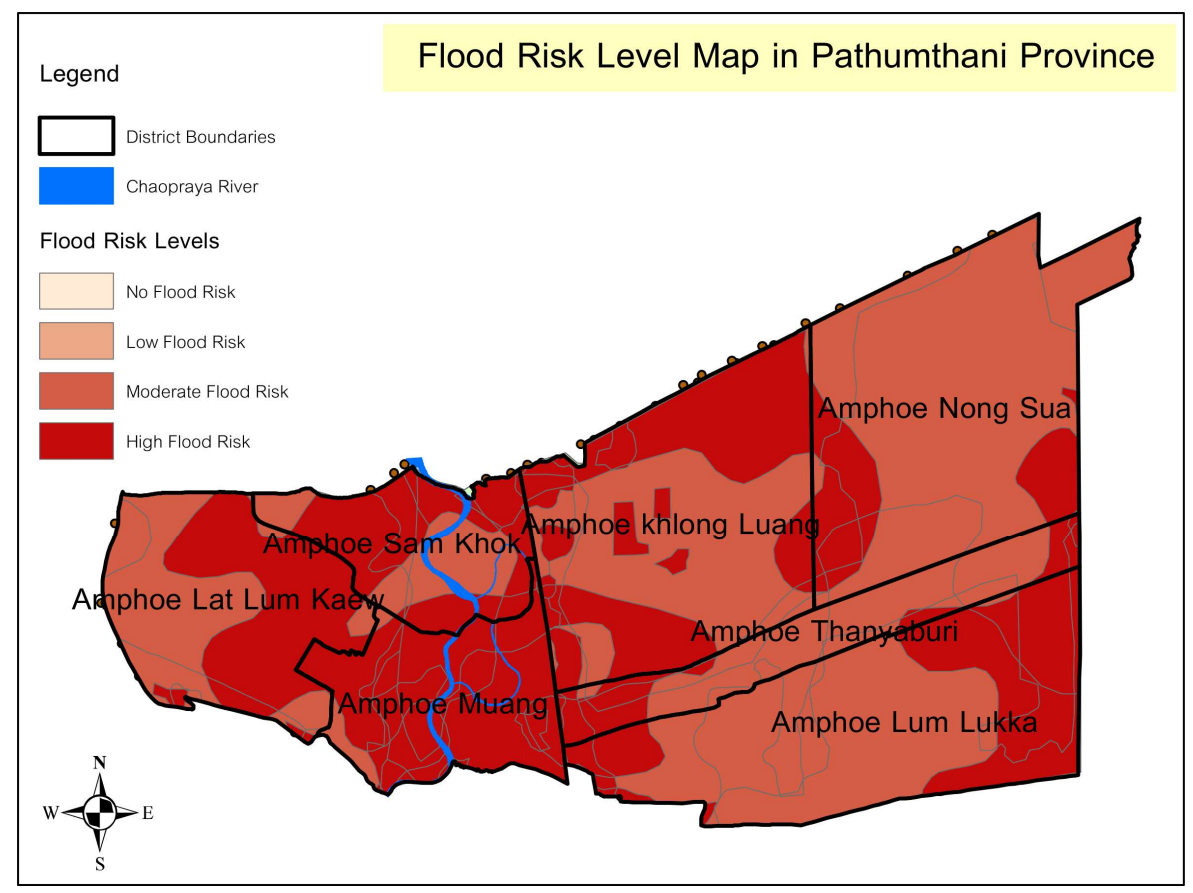

Figure 11. Result Map from Sieve Analysis

Finally, all factors weighted and scored are combined and overlayed to identify the most significant factors contributing to flood impact risk. The result map provides a useful tool and opportunity to raise awareness and enable sustainable development incorporating public participation at the local level. The results map shows areas that could most safely be settled, with the research identifying the high risk areas as the Sam Khok District, Muang District and Lat Lum Kaew District.

\section{EXPECTED OUTCOMES}

The results of this study will be used as guidelines for policies on urban planning for Pathumthani. The guidelines will shed some light on climate change adaptation plans for the province. The results will classify the types of land use changes, identify directions of urban growth, and estimate the risk of flood impacts under climate change in three scenarios:

(1) Improve and develop zoning and building code,

(2) Stipulate flood way and catchment area, and

(3) Develop and present hard structure development projects.

The application of the study will suggest some revisions to local building codes and comprehensive plans of Pathumthani.

\section{CONCLUSION}

Pathumthani has increased high flood risk under a climate change situation caused by rapidly expanding urbanization and urban sprawl uncontrolled. The agriculture and wetland areas have been transformed to accommodate built communities and infrastructure; the inability for existing planning measures and also local plans and policy to control and cope with this land use change is the main concern of the people and policy makers. This research analyzed 
the flood risk areas under climate change to assist in the development and planning of improved local plans to manage and serve as the basis of effective planning policy or planning measures to reduce flood impacts and improve adaptation for communities in these areas.

\section{REFERENCE}

Kornissaranukul, W. (2013). Urban Planning as Mechanism to Cope with Climate Change Risk: Case Study on Flood Risk and Flood Management in Punpin, Suratthani. Bangkok.

Watcharapasakorn, S. (2013). Flood Management and Community's Participation: A Case Study of Nukkeelalamtong Village, Saphansoong District, Bangkok. Bangkok. 